\title{
Sustainable Development of the Built Environment: The Role of the Residential/Housing Sector
}

\author{
Tom Kauko \\ Dept of Geography, Norwegian University of Science and Technology (NTNU), \\ Trondheim, \\ Norway
}

\section{Introduction}

Sustainable cities have existed much longer than the sustainability discourse. From a historical perspective it can be argued that private investment into the built environment was always paramount for creating the great cities where ingenuity flourished in both civic and business arenas. This was the case in late medieval Florence and (perhaps incorrectly) is assumed to be the case in contemporary Manhattan - the 'Florence of our times'. Innovations in the banking-sector tend to generate property investments and eventually the accumulated prosperity further fosters high-level social and cultural life. In other words, sustainable investment practices much steer urban development. When assessing various possibilities for sustainable investment practices, one vital task we cannot escape is to assess the contribution to energy savings that could be made by cities, their buildings and their citizens. To leave it here would however only serve a narrowly defined sustainability agenda that neglects other dimensions than the 'green' ones. In fact, it can be argued that social and economic sustainability issues show more resonance with property investors than that of the older type of environmental-energy sustainability (see Sayce et al., 2007).

According to Goodland (1995) the economic sustainability concept has been applied in practice since the Middle Ages, when merchant traders had to know how much stocks would need to be maintained for securing a continued trading. Today this problem is reformulated as to how much profit is deemed necessary to reinvest in environmental, social and cultural amenities. Interestingly, while Goodland considers the distinction between economic and environmental sustainability subtler than that between the social and environmental sustainability dimensions he nonetheless incorporates a social agenda as he predicts that, rather than relying on growth alone, sharing and population stability will be necessary for attaining a greater equality between rich and poor. Poverty reduction, de facto, is dependent on redistribution and sharing, population stability and community sodality, Goodland notes. In fact, when discussing the social aspect it should be noted that the international sustainability development agreements include poverty eradication as a vital element (Bramley and Power, 2009).

On the other hand, social sustainability is conditional upon environmental sustainability, Goodland (1995) asserts. In the property sector, and if a process oriented view is taken 
(rather than a mechanistic view so typical for the equilibrium traditions), the issue becomes that of making the market for buildings, land use and location quality (including elements of the surroundings). In a more general sense, shaping the market translates onto two analytical key concepts: one is about institutions and the other about the behaviour of market actors. Additionally, the role of production technology comprises a third such concept, albeit for the location less so than for the buildings.

Within this realm the implications for housing, arguably an (if not the most) important sector of the property industry, are many and of great significance: cities don't exist without people, and people need shelter. In this contribution we look at a variety of private as well as public features of housing market sustainability, and in particular from spatial perspectives ranging from the neighbourhood to the city region. Above all, sustainable housing developments also need to be sustainable places to live, and that this requires, above all, dynamic private investments regulated by smart policymaking and flexible public institutions. This formulation recognises that, whatever the particular trajectory of urban development, on top of private investments also public support is required to sustain a credible sustainable development agenda. The key words here are cooperation and adaptability. To cite Vatn (2005, p.434) "We were able to create the large corporation. Why shouldn't we be able to create the grand cooperation? The choice is ours."

Going back to the investment perspectives, following Bryson and Lombardi (2009) the two contrasting ideal types of residential development projects in cities may be summarised depending on whether the goal is maximising short-term profits or reinvesting the extra profits onto sustainability of the project:

- If only profit is considered in the development of housing, the project is unsustainable in the long run.

- If sustainability related motives dominate: normal profits are reaped and the remaining margins are fed back to the use value of the project; this is one of the cornerstones of a sustainable market approach.

For the purposes of this study a conceptual model is developed based on evolutionary economics; here property investments are considered the primary factors for establishing urban sustainability before regulation and planning processes. This line of theorizing underscores the role of diversity in so far as the outcome is allowed to evolve through selection processes. In this chapter two examples, largely based on expert interviews and observation: de Pijp, a neighbourhood in Amsterdam; and the Budapest metropolitan region, indeed demonstrate that the issues at stake are typically, neither problem free nor straightforward (for more profound information about the case studies, see Kauko, 2009; Kauko 2010; and Kauko, forthcoming).

\section{Outlining a theoretical framework for the sustainability of urban residential projects}

As an academic research objective, sustainable buildings and areas are currently approached from three different literatures:

1. The impact of the building on their users - health issues of the workers and residents in particular. 
2. Global impacts: emissions, energy efficiency and renewable energy (see e.g. the literature on passive houses.)

3. Urban and environmental sustainability of cities/city-regions.

The focus of the present paper is on the third tradition: more precisely, about spatial planning or development of areas - both Brownfields and Greenfields. The point here is about incremental changes rather than 'one grand planning vision'. However, it might come as a surprise that, instead of multi-criteria decision methods (MCDM), a 'partial criteria' or 'single criterion' approach, where the economic dimension always comes first, is applied here. Despite the current global shift in emphasis from economic criteria towards ecological ones, this study prefers an alternative logic. The main justification for this selection is that the rolling back of the state has resulted in more local responsibilities in relation to retaining sustainability - this development begun in the early eighties in Western Europe and early nineties in Eastern Europe. Therefore, it is reasonable to assume that, at a local level, the economy comes before other aspects of sustainable development after all. To continue this argument, nowhere is this more so than for real estate projects as these are tied to location even if being global investments. The issue here thus is how the economic sustainability can generate environmental and social sustainability in a given locality (either the urban area as a whole or only a particular neighbourhood of it) by reinvesting the profits made with view on long term developments - following the postulates of Bryson and Lombardi above.

For any sustainable development to occur the ultimate challenge is to prepare for a long time-horizon - say, at least to the next generation, but preferably much longer. If we accept an evolutionary perspective to sustainability - like RICS recently does, see e.g. Macintosh (2010) and Ratcliffe et al. (2010) - the key to success is innovativeness. This requires heterogeneity in product ranges, which in turn is fostered by flexible and market sensible administrative structures and is influenced by the changing tastes of individuals consumers and citizens. Therefore we can purport that real time management is far more important and effective than plans and traditional government bureaucracies. As a consequence, a system based on 'trial \& error' is preferable, of course, rather than 'one giant leap forwards' no matter how well meaning welfare agenda there is in place. Such failure of adaptability can today be seen in places such as the extremely homogeneous, polished and Corbusier-inspired Belarusian capital Minsk: even in a seemingly perfectly environmentally and socially apt context the lack of product diversity will eventually turn into to a problem. At the same time, however, a market-based agenda alone cannot lead us onto the right sustainable development track. It can be argued that we also need the following two elements:

1. Good governance and incentives (such as tax and subsidies), either in the form of public-private-partnership (PPP) or development agreements.

2. Education of all actors involved (including scenarios and forecasting).

It is to observe that economic sustainability is not only about the ( $n$th year) cost savings, but how one reinvests these savings so as to maximise the provision of public amenities, at least one generation ahead. The players involved include bureaucrats, professions, corporations and smaller market actors as well as citizens/residents. Here we identify several factors, namely the impact of the size of the home on carbon-dioxide emissions, whether the focus on the improvement of the sustainability of existing areas ought to be inner cities or suburbs, and the role of new high tech developments situated peripherally in the city 
region. Within each point, we need to assess the role of the government as well as rethink our own behaviour.

McIntosh (2010) points out that we all have the means to shape our future, for example by lobbying a slow government, and furthermore, if we want a sustainable future the private sector has to take the lead. Jones (2010), in turn, purports the issue about setting the limits is about setting error margins of operative space; according to him the issue is also ethical and not only scientific - we need an increasingly trans-disciplinary approach here where the social aspect is integrated into the framework - a more robust transition management, otherwise we face an IPCC type of backlash, Jones warns. Finally, according to Fisher (2010), we need a policy framework based on future and past - in principle, every city and town can be a resilient, prosperous, life-affirming place. Instead of one-size-fits-all policies one needs to know the context dependent starting point, in particular, what kind of housing preferences people express, she concludes.

Economic and environmental sustainability concepts both focus on the longevity of the physical inputs into production. However, in doing so Goodland (1995) refers to "the stewardship approach of safeguarding life-support systems" rather than focusing on intergenerational equity. In other words, consumption needs to be curbed with future production in mind rather than just with future decrease in incomes in mind. Interestingly, he speculates that cutting the consumption of the developed countries by ten per cent is a more feasible expectation that to wait for the developing countries to raise their per capita income levels to the OECD average. Consumption above sufficiency, in other words, living off inherited and finite capital, inevitably leads to unsustainability, Goodland claims. According to him the human economy has become unsustainable due to overconsumption and inapt regulation of pollution and population growth by governments.

While the conventional wisdom is that rules and regulations cannot keep up with the markets (e.g. Ball, 2006), the current financial crisis showed us that the government matters after all for the property market and determination of property values and prices. Thus we realised that we need regulation of the markets, but the question is: who sets the limits, that is to say, how do we determine the sustainability benchmarks that any coercion is based upon? Thus, do we anchor our institutions and policies on completely ad hoc decisions, evidence or ideology? The Nordic countries are a good case in point: due to the absence of population pressure (i.e. of the continental European or British magnitudes), there has not been a serious need to design innovative strategies for community governance and, as a consequence, even one-size-fits-all policies have proven successful on national as well as local levels.

Goodland (1995) notes that the use of the term sustainable development is surrounded by confusion to such an extent that all discussion surrounding it becomes ambiguous immediately. At the classical extremes, we have Malthusian definitions based on finite resources and Ricardian definitions of infinite resources, and in between we have the weak sustainability concept launched by the World Bank in the mid eighties. Within the housing research field, Støa (2009) argues along similar lines that, while sorting out the obscurity and internal conflicts surrounding the concept of sustainability remains a challenge in itself, it is worth to be pragmatic and plan in relation to what we think sustainability is. Støa therefore suggests to apply ones own preferred definitions and to constantly revise ones goals in 
relation to new knowledge of the state of affairs. At the end of the day, for analytical purposes a set of definitions for various kinds of sustainability are required, even if existing definitions often are ambiguous.

Assuming that housing development, and thereby also the housing market, comprise an important element for defining a sustainable place, three issues are pertinent here:

1. A grossly substandard level of housing is unacceptable for health and safety reasons. The quality (largely a subjective indicator though) therefore ought to develop in the same direction and with the same pace as the price level. This is about the site and building specific attributes as well as the characteristics of the surrounding environment, neighbourhood and the city as a whole.

2. It is not sufficient with high quality unless people can afford to buy (or rent) the products. In other words, affordability (often approximated as net income) of the dwelling also ought to develop in the same direction and with the same pace as the price level. It may be found that some of the wealthiest areas are also among the economically least sustainable ones.

3. The diversity of the product ought to be respected. Even if the quality and affordability criteria are fulfilled, it is not sufficient for value stability (and hence economic sustainability) unless there is a wide enough range (i.e. product variety generated for most apt selections to be made) of different quality and affordability levels on the market. This is because the drivers of sustainability: production technology, community governance as well as consumption fashions, all tend to change fast and then it is vital not to have neglected any specific housing package even if it may seem marginal at some stage. (Or put differently, if a potential market trend setter or other innovation in terms of quality or affordability is not recognised this will have harmful impacts for the evolution of the property portfolio in terms of its value stability.)

The three housing market sustainability issues above do not readily fit in to the definitions of the three sustainability dimensions, but are rather combinations of them. Figure 1 synthesises the various facets of the problem area. It should be read as follows:

- Assuming a new type of business culture, economic sustainability (i.e. the investment of extra profits for the long term) can help directly in generating social sustainability (e.g. affordability) and creating 'green' environments. The emphasis here is on the second (rather intuitively) and third (via the evolutionary argument) of the issues above.

- Assuming a new type of culture in civic areas too, social sustainability criteria can also be fulfilled more indirectly, if quality-of-life (QOL) is invested in after economic and physical sustainability is achieved. In principle, this could pertain to all three issues above via their respective logics.

- Value stability implies constant price development in relation to other indicators such as income and quality levels (i.e. all three issues above). This is a much narrower concept than economic sustainability - notably, if the quality or affordability balanced price trend declines it may nonetheless indicate sustainable development with respect to some other aspect that can be considered economic in a broad sense.

- There are some more particular types of sustainability criteria, for example the asset valuation aspect that potentially incorporates elements of all three issues above. Asset valuation here implies that we can include various sustainability indicators onto the valuation using the income approach instead of relying on merely financial indicators. 


\section{Evaluation of sustainability:}

1. Physically ('green')

1. Energy efficiency

2. Renewable energy

3. Emissions

2. Socially

1. Community cohesion

2. Negative externalities

3. Cultural aspects

3. Economic (property market, functional, financial)

1. Value stability

2. Asset valuation

3. Other

\section{The built environment:}

1. Buildings: commercial, residential, other

2. Infrastructure: energy, water, waste, sewage, transport, telecommunications, other

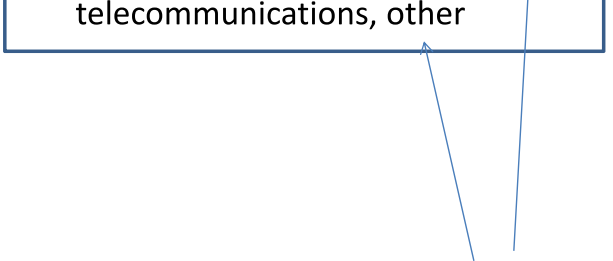

The role of the housing market is twofold

'New business culture': The profit from 3. is reinvested into $1 . \& 2$.

'New other culture': The maintenance of $1 . \& 3$ keeps the inhabitants happy/satisfied The need for technical solutions (e.g. passive houses) remain!

Fig. 1. Evaluation of sustainability in the built environment context.

Using the definition of Kauko (2008) a classification of housing market sustainability to various ordinal classes of sustainability would be a prerequisite to subsequent value modelling in order to determine whether the long-term outcome is of a healthy or distorted kind. In fact, value stability is only one part of economic sustainability as a stable market development is a subordinate concept to an overall dynamic market context required for a 'more total' economic sustainability. In other words, if we observe that the quality adjusted price $(\mathrm{P} / \mathrm{Q}$ ratio) is declining, it then cannot indicate value stability, but may instead imply economic sustainability due to some other criteria, notably viable developments (Jones et al., 2009). On the other hand, such circumstances might also or alternatively be socially sustainable due to safety and cohesion, as perceived by the inhabitants of the place. For example, in Oud-west (the Amsterdam district one of the cases in the present study, de Pijp neighbourhood, is part of, see fig. 2) 1991 and 2001 were particularly unstable years in terms of the recorded $\mathrm{P} / \mathrm{Q}$ ratio, but the area was in fact at the same time (and still is) one of the most socially sustainable in the whole city (see Kauko, 2009). Or vice versa, the recorded price trend suggests value stability, but the development is still deemed unsustainable either economically or socially (as is the case in another Amsterdam district, see fig. 3). Thus, house price trends can be considered unstable but economically or/and socially sustainable; they can also be stable but not sustainable in either of these generic dimensions. 


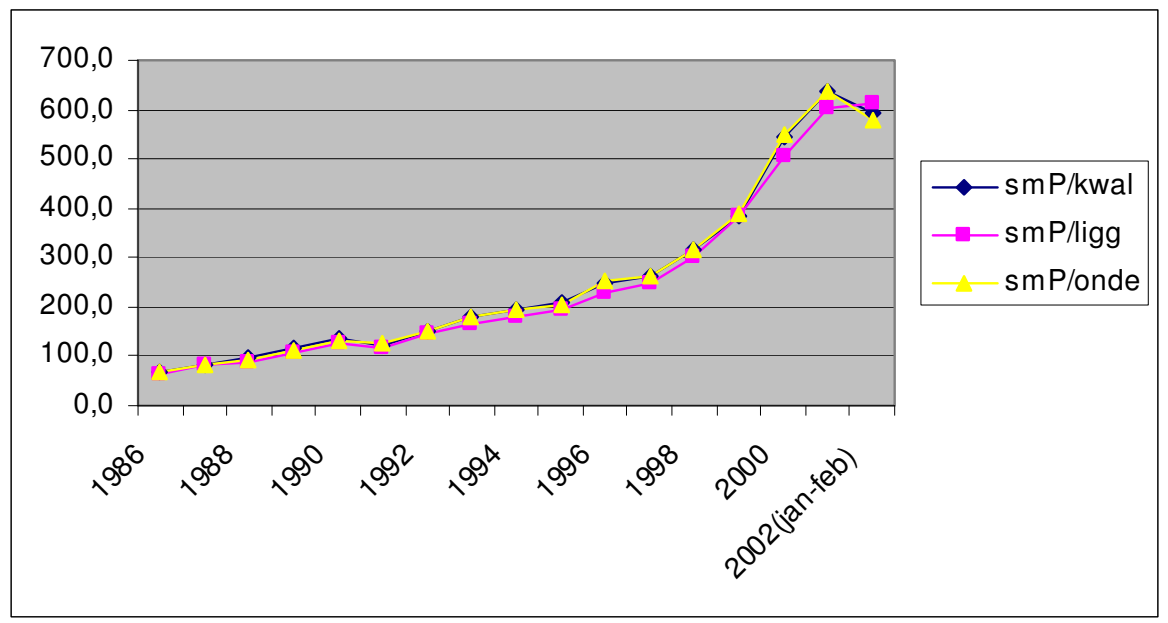

Fig. 2. Oud-west Three $\mathrm{P} / \mathrm{Q}$ indicators: Square-meter price $(\mathrm{SmP})$ in relation to quality level of apartment (kwal); quality level of location (ligg); and maintenance level (onde); levels 1 to 10 assed subjectively by a valuer.

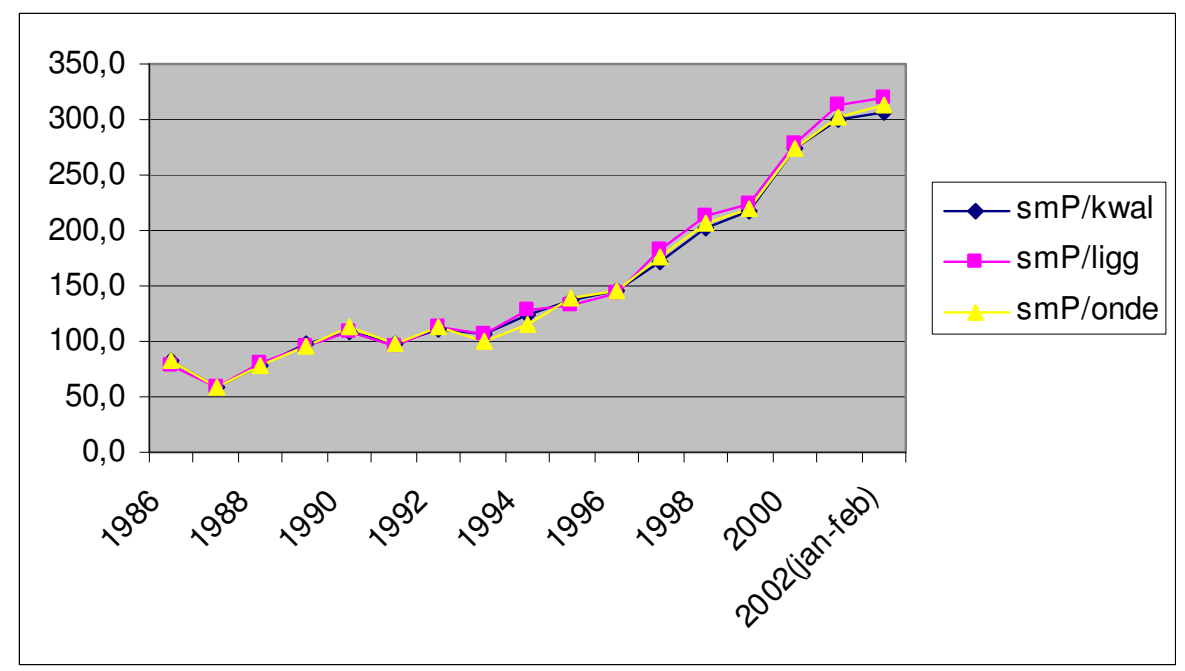

Fig. 3. Geuzeveld-Slotermeer (as in fig 2.).

Following Ratcliffe et al. (2010, p. 4) the key to success is real time management using ICT instead of planning based on ideology and 'one-size-fits-all' regulations/policies. Within a green agenda solutions such as passive houses then become strategies worth trying. Townshend (2006) has a much similar argument: housing quality and design, including the quality of the buildings and their surrounding environment should be given equal weight in relation to housing quantities in urban planning policy. 

Architecture and Building Construction - Agriculture and Food Security

At the outset Manhattan was mentioned as a supposedly sustainable built environment. The reality, however, is not so rosy. ${ }^{1}$ The amount of new building in Manhattan is less than $1 \%$ annually, which does not leave room for creating any kinds of sustainable innovation within a town planning machinery. As a consequence, those who wish to "build more than usually sustainable" need to look at other- even developing - countries, which in itself, is not a rare order of progress, as latecomers in many sectors often develop quicker than the pioneers. If not Manhattan, then what would be an example of a truly sustainable city, given the current circumstances of worsening global problems such as climate change, financial crisis and urban poverty? Probably Berlin then is a better candidate for this nomination, insofar as land use availability is concerned: due to the historical contingencies of that city, ample amounts of building land is provided by sites of what formerly constituted Die Mauer, Tempelhof airport, and inefficiently developed suburban housing estates of East Berlin. On top of that, the German capital is polycentric, affordable, does not suffer from harmful levels of ethnic segregation and so on. In other accounts, Vienna is suggested to be such an urban sustainability leader, and that this is not so much in response to policies or directives, but rather through the 'intrinsic logic' meditated through local actors (Pessina and Scavuzzo, 2010).

The brief discussion on various cities above much sustains the assertion that the economy in itself is insufficient in explaining longer-term urban housing market processes (Ferrari and Lee, 2007). Nonetheless, the economic dimension is prioritised following ideas outlined by Bryson and Lombardi (2009): the message here is to reinvest the profits made and also regulate the property market in order to eventually obtain the resources required for improving the other sectors of 'the sustainability cake'. The context matters, in other words, a locally tailored fit of the model of ecological, environmental, social, cultural, financial and economical sustainability is necessary. The approach chosen for the present paper is an economic one in the broadest possible sense as it also incorporates government interventions: here a controlled local market is necessary in order to avoid the mistakes of the past. The key to understanding here is to examine why certain areas are successful with respect to given criteria and others are less so. This results in "best practice" and eventually in new theory. When the reasons are clarified the issue becomes one about how to apply that theory for another place, but so that the particular context is taken into account. However, prioritizing one dimension, like here the economic one, is necessary to reach practically relevant results.

To sum up the argument so far, it can be assumed that a sustainable development of the built environment, including economic and socio-cultural sustainability, necessitates incentives for consumers as well as community governance. Tragicomically strict regulation of everything a la Minsk, just comic lock-inns of Manhattan, the favourable but somehow alternative path-dependence of Berlin, and the curious bottom-up trajectories of Vienna all illustrate the multitude of urban settings in this context. Many of the preconditions for sustainability originate in privately initiated residential property development and housing market processes. While environmental-ecological sustainability comprises the most common criteria and social-cultural criteria for sustainability exists too, the emphasis of this study is on economic sustainability, as defined as follows: affordable housing, quality control and product diversity.

\footnotetext{
${ }^{1}$ As the former town planning chief of the city of Manhattan informed me during a session at the ISEE conference, 23 August 2010, Oldenburg, Germany.
} 
To the extent such ideals correspond with the reality is exemplified below by two cases: one on the neighbourhood level and the other on a metropolitan level. When designing the method one should note that, only by comparative research one can isolate the institutional and behavioural elements that make the marketplace sustainable to a varying degree. The methodology comprises analysis of the sustainability of urban property developments using house price data together with other local information collected from documents and expert interviews.

\section{De Pijp in Amsterdam²}

The neighbourhood de Pijp in the inner city of Amsterdam (see fig. 4) is seen as one of the classical examples of Dutch urban restructuring processes, as the pro-market change in policy has led to an upgrading of de Pijp. Both individual action (organic change) and government policy and subsidy have initiated the renewal. It has mainly been about dwelling improvement, whereas demolishing and new building development have taken place sporadically. Housing corporations, investors, who own a small number of dwellings, and individuals, including the renters and the homeowners themselves are the main actors, rather than large-scale private owners.

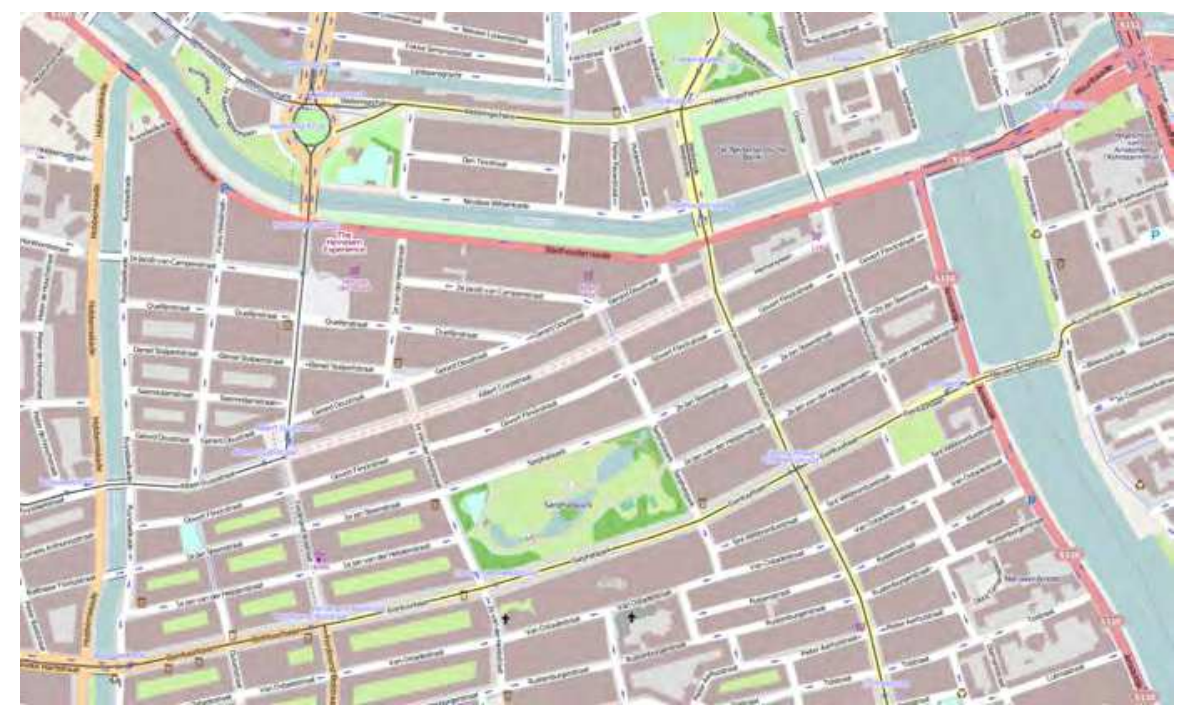

Fig. 4. Map of de Pijp

The described redevelopment is indicative of a shift from a traditional 'active' government towards a more 'passive' type of government. Nevertheless, public regulations are still in place in the Netherlands. It is worth noting that buyers have got tax incentives to buy apartments and housing associations have got incentives to sell their stock (Aalbers, 2008, p. 157). What perhaps is more relevant is that, in Amsterdam, the social housing is still hugely significant (only $21 \%$ owner-occupation on the city level; $16 \%$ in de Pijp).

${ }^{2}$ See Kauko (2010) for a profound discussion on the revitalization of de Pijp. 
On the other hand, even though rehabilitation is supposed to have taken place here, neither the dwelling quality nor the quality of the micro-location has increased, when examining the findings of a quasi-controlled experiment (see Kauko, 2009). In fact, here is a contradiction between this conclusion and the media discourse. Which is a more valid claim, that a particular dataset has not captured the change in quality that, according to popularised information, has occurred since the 80s, or that the reputation of an upgraded de Pijp is not at all factual, but merely based on hearsay and media spun discourse?

How much of the perceivably successful regeneration outcome really is sustainable in terms of economic, social or environmental criteria? Can we also conclude that the housing market upgrading has been successful? Here one cannot make definite conclusions due to the fragmented and speculative nature of the evidence. In particular, it was observed that the economic and quality development of the neighbourhood is uneven across house types and microlocations (i.e. only certain buildings or blocks, namely those built in the style of the interwar years, experienced a price lift during the period of examination from 1986 to 2002.) Even if the area under study was small, the quality and affordability varied greatly, which in itself indicates a wide diversity of available housing market products. On the positive side, both demand and supply led mechanisms of institutional change towards a more sustainable outcome driven by incentives were observable in de Pijp.

To sum up the evaluation of de Pijp, economic sustainability exists in relation to the product diversity criterion, but otherwise the evaluation is contradictory given that the price (and ostensibly rent) level far too often is unaffordable; another issue is that arguably the area can be perceived as rather messy. Both problems have to do with decreased government involvement in the renewal processes.

\section{The Budapest region ${ }^{3}$}

Hungary is a rather one-sided economy, where Budapest attracts talents from the rest of the country. At the same time, the density in terms of households is declining in Budapest. This is manifestation of a variety of reasons: the new dwellings are bigger, household size is shrinking and people are increasingly moving from the city to the urban periphery of the agglomeration (see Fig. 5, over). What many are wondering is how a relatively wellfunctional society (in the early days after the transition) has deteriorated into one with all kinds of problems. While a range of factors have played their parts, arguably the main reason lies in the extreme neo-liberalism implemented under the socialist-liberal rule 20022010. As a part of this mismanagement, the current housing market situation in Hungary can be characterised by a falling demand caused by the financial crisis of year 2008 together with an oversupply originating from an earlier speculative building activity.

Undoubtedly, in many Western countries a relatively centralised approach has been the key to creating successful housing environments. This has to do with path dependency of political and policy routes taken at the time when building the welfare state was deemed the ultimate goal after WW2 (in some countries already since the early 19th century). In a Central Eastern European (CEE) context such an approach has obviously been unpopular since the

\footnotetext{
${ }^{3}$ This section makes a brief summary of Kauko (forthcoming).
} 


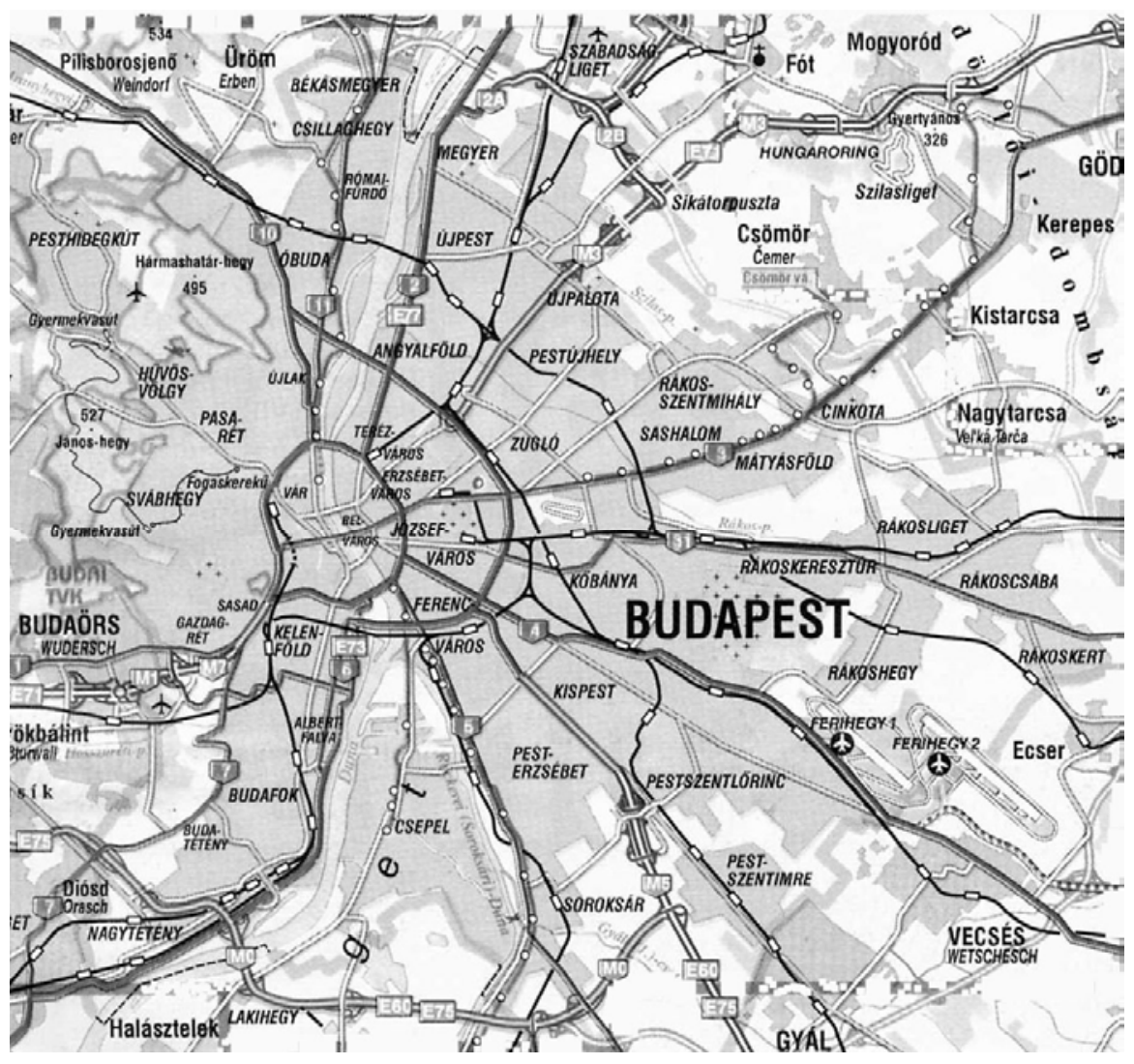

Fig. 5. The Budapest region.

transition. At present, in Budapest planning and policy is still rather decentralized and fragmented. Such a state of affairs cannot be considered sustainable (even with goodwill).

The reality of this near total (un)sustainability can be exemplified with the Hungarian type of gated communities (residential park, lakópark, lakókert). First of all, as elsewhere, the environmental-ecologic sustainability criterion may also remain unfulfilled if the costs are minimised (except perhaps in the most modern niche market cases). Then, the residential park is arguably not socially sustainable either as it segregates the wealthy from the poor, which was condemned in the second section. This, of course, works against the lakópark agenda. Finally, looking at the economic sustainability, a number of obvious shortcomings can be found with residential parks:

1. The quality of the location is often poor - at least in the more recent products which are marketed for the middle-class housing consumers.

2. In some cases the same can be said about the building quality - where costs have been pressed down in order to attract younger families and first-time buyers.

3. The market situation is marred by diminishing demand and already existing oversupply, which means that trying to sell these products is difficult and many such 
dwellings risk remaining vacant for a long time. It is speculated that, in twenty years time, the lakópark will be perceived as unfavourably as the lakótelep (panel built housing estate) is perceived today.

Going back to our theoretical issues, in the Budapest region the quality varies sharply across locations, and correlates negatively with the age of the building. Thus older buildings, often in the inner city or in the housing estates, are mainly of low quality, whereas the newly built projects are mainly of a better quality. Affordability is however low overall. The differentiation across new built products is low, however, as the global investments seem to apply much standardised building concepts, notably the lakópark. To a large extent, the increasing differences in quality as well as the narrow range of new products are due to an increased share of private sector driven property developments. Whereas during the late nineties also the public sector could participate in PPP types of urban regeneration, nearly all urban development projects today are privately financed, often also by global capital.

Because of all this one is entitled to criticise the actions of the government and lack of planning policy in these circumstances. Nevertheless, by the same token one is entitled to be optimistic, now that the new government has officially included sustainable development rhetorics in its documents that affect housing developments. Housing construction is furthermore seen as a potential boost for the depressed Hungarian economy.

To sum up this case, due to the lack of any coherent backup by a planning system, currently the housing and housing market development in the Budapest region is unsustainable in all dimensions. While there are promising plans underway after the new government took place in May 2010, it is not sure as to whether public support will be targeted correctly, i.e. to most optimal locations, house types and consumer segments.

\section{Conclusion}

Beneath the global discourses, EU frameworks and national guidelines, two different spatial levels are crucial for observing the contemporary issues related to housing market sustainability: the local and the regional. To be able to capture the essence of sustainable market development, in both cases we must begin to realise the potential long-term economic benefit arising from convergence of the motives of the people on one hand and the corporate decision makers on the other. This includes also social and ethical values. Here some of the most important issues concern density and land use. Are for example, the Nordic countries sustainable? Perhaps, but this is 'no thanks' to good governance, as these circumstances experience relatively problem free situations due to a lack of population pressure. And to reiterate the key point of this argumentation: to promote diversity is better than a one best way, as variety leads to selection.

The two cases reached largely different evaluations of economic sustainability of residential developments and sustainable housing market. Whereas de Pijp at least could pride itself on the diversity issue, the current state of affairs in the Budapest region reached a rather miserable verdict. We cannot, however, compare the two cases analytically as one is a region and the other is neighbourhood. Therefore any normal conclusions from comparable studies cannot be made here. Instead these cases have shown how the housing market structures and processes affect the sustainability of the built environment on two very different spatial scales. 
The conclusions of the theoretically informed case studies are that sustainable urban housing development is ideally, just, convivial, functional and aesthetic, possibly with a stable property value development but, in any case, a dynamic market process that encourages innovations in investment and management activity. However, many of these qualities are tradeoffs by definition. In particular, this is the case between value stability metrics (e.g. P/Q) and other economic and social sustainability subcategories. This study has argued that, in principle, such ideal residential environments can only be maintained through long term private investment processes that coexist together with apt public sector interventions. The case studies each showed how the neglect of the latter point plausibly can affect a sustainability evaluation negatively on a given spatial level ranging from the neighbourhood to the city region.

From these findings we can derive further arguments about how to attract potential inmovers using a well-geared socially or economically sustainable competitiveness strategy based on housing market regulation. In this context it is to observe that, while migration as such is, on balance, considered favourable for the host society from both general economic and social points of view, the problem is the fit between the transition periods of migrants and the regulations (Varga, 2010). Hence the way behavioural and institutional factors play out determines the sustainability position of a given territorial unit in terms of its real estate and housing situation - first along the economic dimension and subsequently along other dimensions. As van Weesep (2000) already over a decade ago put it: housing policy still matters in the New Economy.

\section{Acknowledgment}

This paper is an improved version of my contribution for a RICS Symposium "Meeting The Challenges of the Housing Economy: an international perspective", 8-10 September 2010, Edinburgh, UK. I am grateful for all colleagues present, for valuable comments that helped me improve the paper into a publishable shape. Furthermore, the ISEE conference (2010) in Oldenburg, Germany, also helped me concretize some of my arguments.

\section{References}

Aalbers, M.B. (2008) The Financialization of Home and the Mortgage Market Crisis. Competition \& Change, Vol.12, No.2, (June 2008), pp. 148-166, ISSN 1024-5294

Ball, M. (2006) Markets \& Institutions in Real Estate Construction, Blackwell Publishing, ISBN 978-1-4051-1099-0, Oxford, UK

Bramley, G. \& Power, S. (2009) Urban form and social sustainability: the role of density and housing type. Environment and Planning B: Planning and Design, Vol.36, No.1, pp. 30-48, ISSN 0265-8135

Bryson, J.R. \& Lombardi, R. (2009) Balancing Product and Process Sustainability against Business Profitability: Sustainability as a Competitive Strategy in the Property Development Process. Business Strategy and the Environment, Vol.18, No.2, (February 2009), pp. 97-107, ISSN 0964-4733

Ferrari, E. \& Lee, P. (2007) Changing Spatial, Ethnic, and Tenure Patterns in England. In: Neighbourhood Renewal \& Housing Markets: Community Engagement in the US \& UK, H. Beider, (Ed.), 31-62, Blackwell Publishing, ISBN 978-1-4051-3410-1, Oxford, UK 
Fisher, R. (2010) The Role of Local Government in Designing Sustainable Cities. Presentation at the EU Sustainable Energy Week (EUSEW), 22-26 March, Brussels.

Goodland, R. (1995) The Concept of Environmental Sustainability, Annual Review of Ecology and Systematics, Vol. 26, (November, 1995), pp. 1-24, ISSN 0066-4162

Jones, C., Leishman, C. and MacDonald, C. (2009) Sustainable urban form and residential development viability. Environment and Planning A, Vol.41, No. 7, pp. 1667-1690, ISSN 0308-518X

Jones, P.T. (2010) Terra Reversa - The Phased Transition to Sustainable Living. EU Sustainable Energy Week, 22-26 March, 2010, Brussels.

Kauko, T. (2008) From modelling tools towards the market itself - an opportunity for sustainability assessment? International Journal of Strategic Property Management, Vol.12, No. 2, pp. 95-107, ISSN 1648-715X

Kauko, T. (2009) Policy impact and house price development at the neighbourhood-level - a comparison of four urban regeneration areas using the concept of 'artificial' value creation. European Planning Studies, Vol.17, No.1, pp. 85-107, ISSN 0965-4313

Kauko, T. (2010) An evaluation of the sustainability of inner city residential projects, Housing, Theory and Society, Vol. 27, No. 1, pp. 1-20, ISSN 1651-2278

Kauko, T. (forthcoming) End in sight? On the (un)sustainability of property development in the Budapest region. International Journal of Strategic Property Management, ISSN 1648-715X

McIntosh A. (2010) Visions of Tomorrow to Plan our Lives Today - Sustainable Development and the Real Estate Industry. EU Sustainable Energy Week, 22-26 March, 2010, Brussels.

Pessina, G. \& Scavuzzo, L. (2010) From Crisis to Innovation: Searching for the Roots of the Sustainable Development of Vienna. EURA Conference, 24-26 September, Darmstadt, Germany.

Ratcliffe, J., McIntosh, A. \& Brown, S. (2010) Built Environment Foresight 2030: the sustainable development imperative. RICS Foundation, The University of Salford, Futures Academy and King Sturge.

Sayce, S., Ellison, L. \& Parnell, P. (2007) Understanding investment drivers for UK sustainable property. Building Research \& Information, Vol. 35, No. 6, pp. 629-643, ISSN 0961-3218

Støa, E. (2009) Housing in the sustainable city - issues for an integrated approach. In: HoltJensen, A. and Pollock, E. (Eds): Urban Sustainability and Governance: New Challenges in Nordic-Baltic Housing Policies. Nova Science Publishers, ISBN 978-1-60456-886-8, New York, pp. 31-48.

Townshend, T. (2006) From Inner City to Inner Suburb? Addressing Housing Aspirations in Low Demand Areas in NewcastleGateshead, UK. Housing Studies, Vol.21, No.4, pp. 501-521, ISSN 0267-3037

Van Weesep, J. (2000) Housing policy - the link between welfare and economic development. Journal of Housing and the Built Environment, Vol. 15, pp. 165-181, ISSN: 1566-4910

Varga, A. (2010) Migration trends of Accession. Open days, $8^{\text {th }}$ European week of cities and regions, Brussels, 4-7 October, Workshop 05Univ01: Urban Dynamics: Migration and social mobility? Available from:

http://ec.europa.eu/regional_policy/conferences/od2010/reg_frame.cfm?nmenu $=500$ [Accessed 4 January, 2011]

Vatn, A. (2005) Institutions and the Environment. Edward Elgar, ISBN 1-84376-100-9, Cheltenham. 


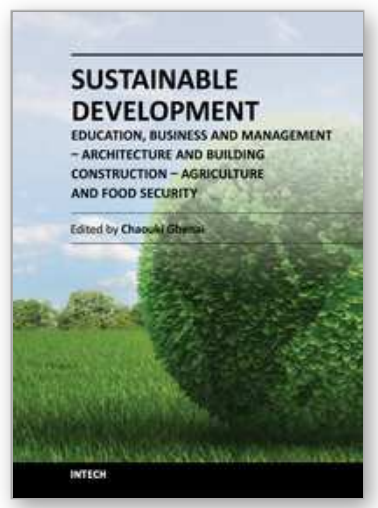

\author{
Sustainable Development - Education, Business and Management \\ - Architecture and Building Construction - Agriculture and Food \\ Security \\ Edited by Prof. Chaouki Ghenai
}

ISBN 978-953-51-0116-1

Hard cover, 342 pages

Publisher InTech

Published online 07, March, 2012

Published in print edition March, 2012

Securing the future of the human race will require an improved understanding of the environment as well as of technological solutions, mindsets and behaviors in line with modes of development that the ecosphere of our planet can support. Some experts see the only solution in a global deflation of the currently unsustainable exploitation of resources. However, sustainable development offers an approach that would be practical to fuse with the managerial strategies and assessment tools for policy and decision makers at the regional planning level. Environmentalists, architects, engineers, policy makers and economists will have to work together in order to ensure that planning and development can meet our society's present needs without compromising the security of future generations. Better planning methods for urban and rural expansion could prevent environmental destruction and imminent crises. Energy, transport, water, environment and food production systems should aim for self-sufficiency and not the rapid depletion of natural resources. Planning for sustainable development must overcome many complex technical and social issues.

\title{
How to reference
}

In order to correctly reference this scholarly work, feel free to copy and paste the following:

Tom Kauko (2012). Sustainable Development of the Built Environment: The Role of the Residential/Housing Sector, Sustainable Development - Education, Business and Management - Architecture and Building Construction - Agriculture and Food Security, Prof. Chaouki Ghenai (Ed.), ISBN: 978-953-51-0116-1, InTech, Available from: http://www.intechopen.com/books/sustainable-development-education-business-andmanagement-architecture-and-building-construction-agriculture-and-food-security/sustainable-developmentof-the-built-environment-the-role-of-the-residential-housing-sector

\section{INTECH}

open science | open minds

\author{
InTech Europe \\ University Campus STeP Ri \\ Slavka Krautzeka 83/A \\ 51000 Rijeka, Croatia \\ Phone: +385 (51) 770447 \\ Fax: +385 (51) 686166 \\ www.intechopen.com
}

\author{
InTech China \\ Unit 405, Office Block, Hotel Equatorial Shanghai \\ No.65, Yan An Road (West), Shanghai, 200040, China \\ 中国上海市延安西路65号上海国际贵都大饭店办公楼 405 单元 \\ Phone: +86-21-62489820 \\ Fax: $+86-21-62489821$
}


(C) 2012 The Author(s). Licensee IntechOpen. This is an open access article distributed under the terms of the Creative Commons Attribution 3.0 License, which permits unrestricted use, distribution, and reproduction in any medium, provided the original work is properly cited. 